Arte, Individuo y Sociedad

ISSN: 1131-5598

http://dx.doi.org/10.5209/ARIS.58831

\title{
San Pedro de Cardeña en carne viva, una conversación con Juan Vallejo
}

Eliana Alvoz

\section{Introducción}

Juan Vallejo (Burgos, 1949) artista polifacético ha trabajado en el silencio monástico de San Pedro de Cardeña (bóveda de la escalinata imperial) y también en la abadía Benedictina de Santo Domingo de Silos (Sileuros, óleo de 6.15x 6 mtrs.). Allí entre el ora et labora de monjes blancos y monjes negros, vela parte de su obra en un memoria que es arte, luz y misticismo.

Desde su primera exposición en el Arco de Santa María en 1968 ha expuesto constantemente, no solo a nivel local, sino también en Zaragoza (1975), Zamora (1995), entre otros, y premiado en 1981 con el Primer Premio Nacional de Acuarela Caja de Madrid.

En los últimos meses su obra ha estado muy presente en Burgos, parte de ella se exhibió en el CAB (Centro de Arte de Burgos Fundación Caja de Burgos, desde 09 de junio de 2017 al 24 de septiembre de 2017) bajo el título Doble Espiral comisariada por Javier del Campo. En abril de 2018, se inaugurará en el Fórum la retrospectiva Memoria (del 19 de abril al 17 de junio) donde Vallejo en relación a su compromiso con la Memoria Histórica ha querido reflejar las dos vertientes de la contienda, las dos Españas que le ha vivido. Con motivo de este alarde a la memoria, tuvimos la ocasión de entrevistar al artista, en relación a su obra primigenia, la gran desconocida por el público, dado que se cobija bajo el manto de la clausura monástica, nos referimos a su obra realizada en San Pedro de Cardeña entre 1971-1972.

\section{Eliana Alvoz en conversación con Juan Vallejo}

EA: Han pasado 47 años de la realización de su obra en San Pedro de Cardeña ¿Podría relatarnos cómo surge el encargo de pintar la bóveda imperial? ¿Conocía a los monjes?

JV: Cuando se quemó el Monasterio en $1967^{1}$, los monjes no tenían dinero para poder reconstruirlo... Habían pedido ayuda al Ayuntamiento, pero éste les volvió

1 El 1 de febrero de 1967 un incendio destruye dos terceras partes del edificio, aunque no ha afectado a piezas histórico-artísticas. Las llamas - sofocadas por los bomberos de Burgos, el Ejército, la Guardia Civil y los propios monjes - han destruido la techumbre de la fachada Sur y buena parte de la Norte, también la carpintería, la hospedería y las dependencias donde los monjes elaboran su conocido licor Tizona. Anónimo, El Diario Palentino-El Día de Palencia, 4 de febrero de 1967. 
la espalda. Entonces el constructor Ángel Blanco Escudero se encerró en Cardeña y allí les dio a los monjes todo el material que necesitaban para reconstruir la abadía. Mientras tanto, el coronel de aviación Hermogenes Díez Fernández de la base aérea de Villafría, dejó varios soldados, carpinteros, soldadores, etc., para rehacer la hospedería porque el monasterio estaba patas arriba. En aquel entonces, yo estaba bajo armas haciendo el servicio militar en Villafría, pero tenía permiso indefinido.

Había estado en Madrid en la agrupación del aire y había pintado varias cosas para los murales del ejército, fue entonces cuando Hermogenes, que era amigo del abad le comento a éste sobre mi trabajo. De este modo, me presentó al abad y a la comunidad monástica. Sin embargo, el abad me preguntó: ¿qué podrías pintar? Esto, le respondí-señalándole- la bóveda. Fue así como me encargaron los bocetos.

Más tarde vino Antonio Cobo Sotos ${ }^{2}$, quien aprobó los bocetos y sugirió, que pintase algo antes de empezar con la bóveda Imperial (bóveda octogonal que descansa sobre pechinas). Entonces mientras se construía el andamio a base de álamos y chopos entrelazados con cuerdas y cuñas [Fig. 1, 2 y 3], realizado a partir del material restante de la restauración, pinté los Siete pecados capitales (1971) situado en la galería de la hospedería.
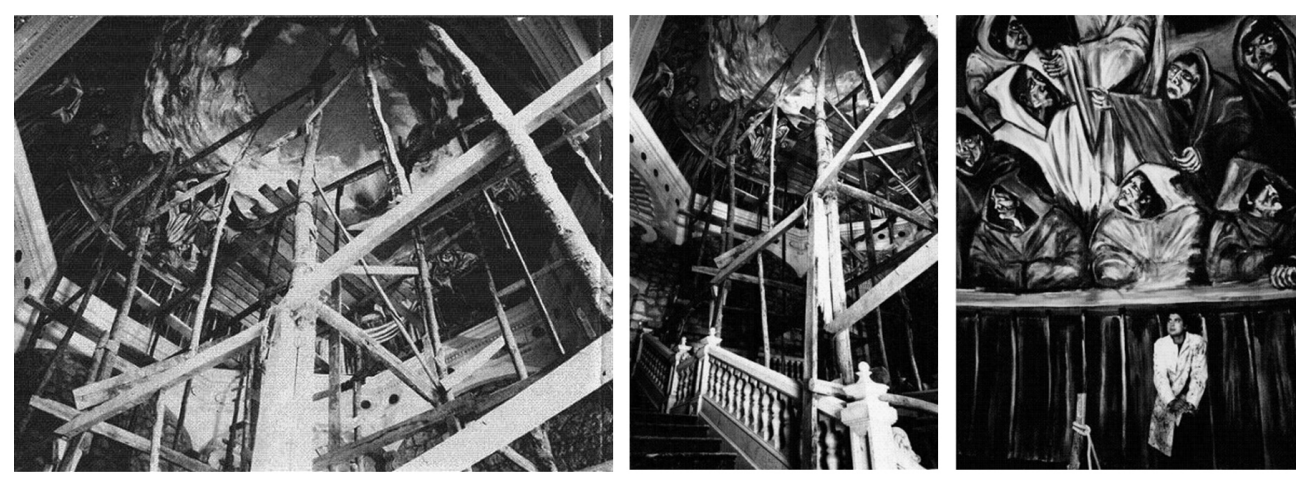

Figura 1, 2 y 3. El día en que se desmontó el andamio. Fotos: Cirilo Saiz en julio de 1972.

\footnotetext{
En el diario $Y a$ se combinaba la actividad de Lafuente Ferrari con la desarrollada por Antonio Cobos y Ramón D. Faraldo. Es en 1953 cuando Antonio Cobo Sotos aparece como el único crítico de arte del diario. Su línea de comentario era conservadora, difiriendo con Castro Arines en Informaciones, mucho más abierta. A partir de 1956 en los escritos de las críticas artísticas se simultanean Cobos Sotos y Ramón Faraldo. El primero, iniciados los sesenta, seguía centrado en los Salones de Otoño o en la Antología organizada por la Asociación Española de Críticos de Arte, mientas que Faraldo prestó mayor atención a las nuevas corrientes en la pintura moderna. En línea: http://www.aacadigital.com/contenido.php?idarticulo=626 [consulta: 10 de octubre de 2017].
} 


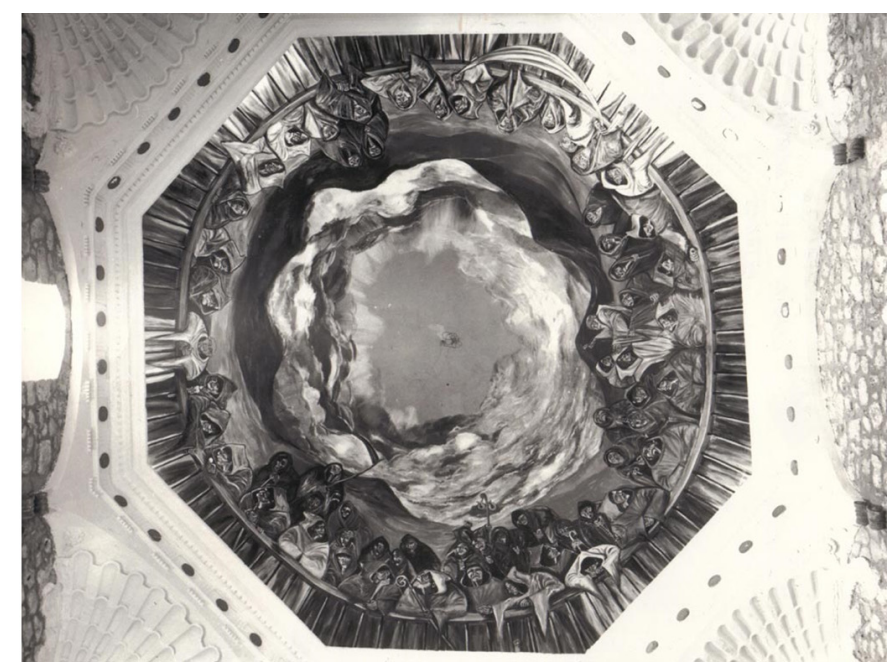

Figura 4. Bóveda de la Escalera Imperial de 1971 - 1972 donde se puede ver la obra completa. Foto: Cirilo Saiz.

Marché a Roma y allí realicé el boceto que doné y que esta exhibido a los pies de la escalera. La influencia venía de donde había vivido: mi domicilio al lado de san Antonio de la Florida en Madrid, donde visitaba la tumba de Goya casi a diario, y la balconada donde reflejó el milagro de san Antonio, supuso una lección inolvidable para mis dieciocho años de entonces.

Ahora, cincuenta años después, sigo entusiasmado como el día en que el abad Sergio y la comunidad cisterciense abrazaron el proyecto de pintar los murales de la bóveda de la escalinata imperial de Cardeña. Actualmente, cuando asumo el reto de mis exposiciones, casi siempre monográficas y densas, como Misticismo abstracto, el Arte en la memoria, Doble espiral, etc., siento algo parecido a aquel reto monástico que tanto ha influido en mi vida y en mi obra.

EA: ¿Siempre tuviste la idea de reflejar la vida del Monasterio como la bóveda de Goya?

JV: Yo cogí la forma de Goya, es decir, la balconada y que los personajes se asomen [Fig. 4]. Pero el tema es totalmente distinto, la vida de los monjes. La escatología de los monjes, la angustia de los monjes, las elucubraciones, sus éxtasis, las confidencias, la curiosidad, el bien y el mal, el misticismo, ahí está todo. 


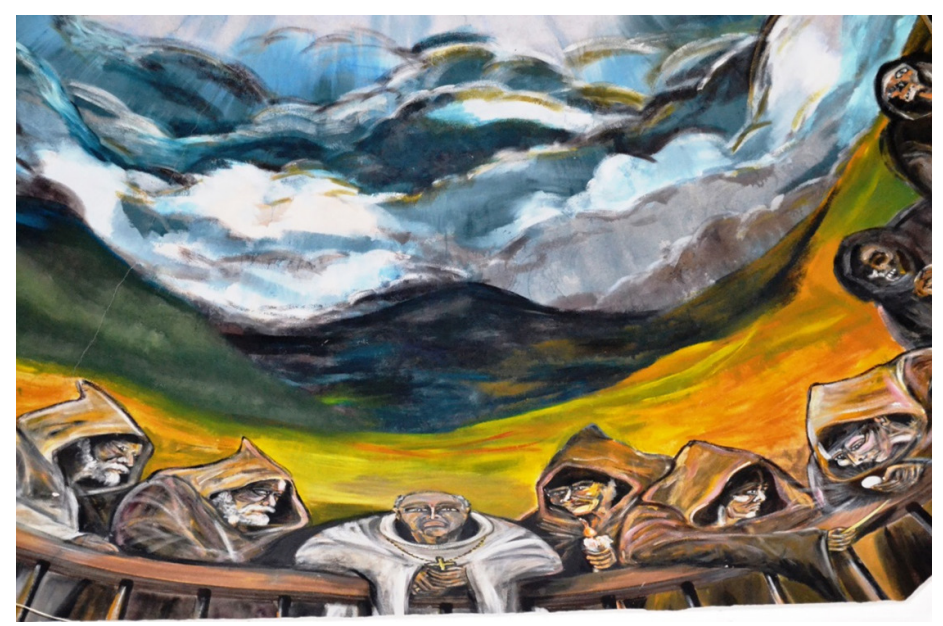

Figura 5. Detalle de la cara oeste del octógono de la bóveda. En él de forma iconográfica se alude a la sabiduría y a la historia. Juan Vallejo, Bóveda Imperial del monasterio de San Pedro de Cardeña, fresco, 1971-1972. Foto: Eliana Alvoz.

EA: Al contemplar la estética formal de la bóveda, además de recordarnos las pinturas negras de Goya, los paisajes rememoran al Greco...

JV: A través de la balconada vemos al oeste apoyado el abad [Fig. 5]. De este modo, en la cara del sol poniente, se refleja la sabiduría y la historia. Proyectadas por quien rige la abadía, el abad, que luce el hábito blanco y el pectoral. Pero también, esa sabiduría se exhibe con la luz que desprende la vela encendida, que sostiene el joven monje que se sitúa a su derecha. La conexión entre la historia y la sabiduría se encuentra en los rostros atemporales, no personalizados, de los ancianos que lucen barbas blancas.

En la cara noroeste, la Eucaristía. Al Norte, se sitúan monjes orantes, que en éxtasis claman al cielo. El paño blanco, no solo es un guiño al Goya de Antonio de la Florida, sino que sirve para romper la monotonía de los barrotes y para hacer el enlace entre el monje joven y el viejo, que podrían ser retratos de Fernán González, o bien, de Abraham. Al Este, San Bernardo con la mano en alto [Fig. 6], acompañado por dos monjes blancos y la historia de la tizona ${ }^{3}$; y en última instancia, la muerte, el fin postrimero de los monjes. Al Sur, el peregrino y las tentaciones. Finalmente, al Suroeste la muerte.

El telón de fondo que se proyecta a modo de paisaje cuyos colores recuerdan al Greco, es la Sierra de la Demanda, señal de la autenticidad de Castilla, en otoño, invierno, primavera y verano.

Recordemos la importancia que tiene la figura del Cid para el abadía, pues, en tiempos del abad Sancho, dio cobijo a doña Jimena, esposa del héroe castellano Ruy Díaz (1043-1086), el Cid Campeador, y sus dos hijas. Por otra parte, los monjes elaboran el licor Tizona. En un anuncio se publicitaba dicho licor de la siguiente manera: "Licor TIZONA EL CID de probada hidalguía, confortante después de la comida y fina invitación a cualquier hora del día. NAVIDAD FELIZ CON TIZONA DEL CID. Fabricado por los PP. Cistercienses, San Pedro de Cardeña (Burgos). Representante: D. Pedro González Antolines, Guzmán el Bueno, 4, Palencia”. Anuncio publicado en El Diario Palentino-El Día de Palencia, 23 de diciembre de 1968. 


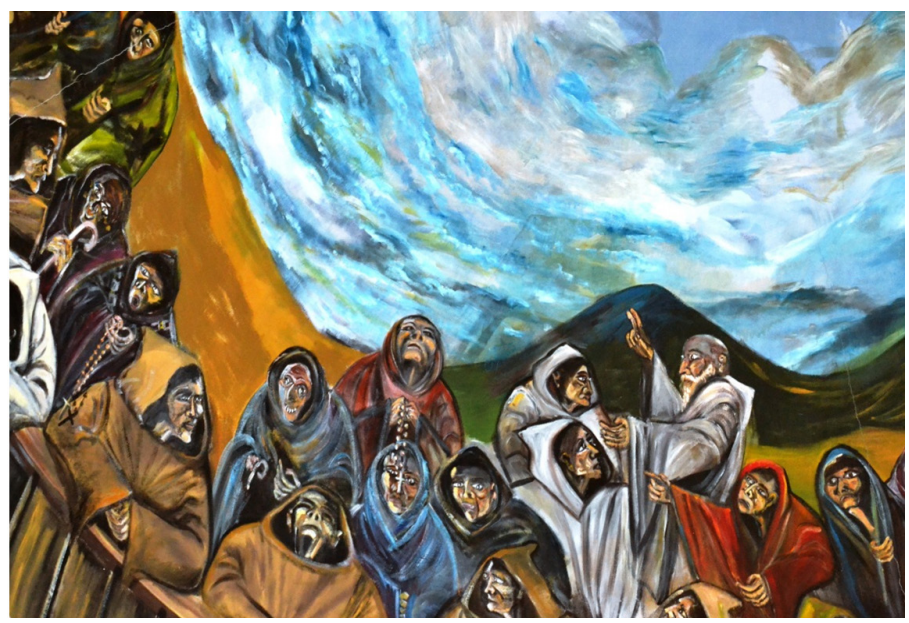

Figura 6. Detalle de la cara este del octógono de la bóveda. En él destaca la figura de San Bernardo de Claraval refundando el monasterio. Juan Vallejo, Bóveda Imperial del monasterio de San Pedro de Cardeña, fresco, 1971-1972. Foto: Eliana Alvoz.

EA: Al tiempo que preparaba los frescos, pinta Los Siete Pecados Capitales tema que reflejaron artistas como Durero, El Bosco, Martín de Vos, Pieter Bruegel, entre otros, sin embargo, la obra de estos artistas es reflejada de forma tenebrista y alejada de la humanidad. Lo que usted nos presenta en estos lienzos (que fueron recientemente restaurados en el 2013) es un modo de entender los pecados capitales de forma innovadora y sugerente, cargados de geometría, color, abstracción, corporeidad, surrealismo lírico... ¿ ¿en qué se inspiró?

JV: Son Los Siete Pecados Capitales de los monjes, no del mundo [Fig. 7 y 8]. Éstos son el reverso de los pecados del hombre. Es decir, la envidia de ellos, es una envidia de la santidad. La lujuria de ellos es la gran ramera del Apocalipsis, las tentaciones de los santos...

EA: ¿Los monjes de ese momento lo entendieron así?

JV: Los monjes pasaban de todo. El abad estaba encantado por lo innovador del proyecto. De hecho, cuando acabo toda la historia, cuando se desmontó el andamio, me confesó: "Juan mira no te he querido decir nada porque conocemos tu carácter y genio, pero hemos recibido cartas anónimas diciendo ¿cómo había osado yo de meter a un pintor, tan revolucionario, tan joven, sin apenas experiencia, etc.? Nos han llegado cartas preocupantes...". 

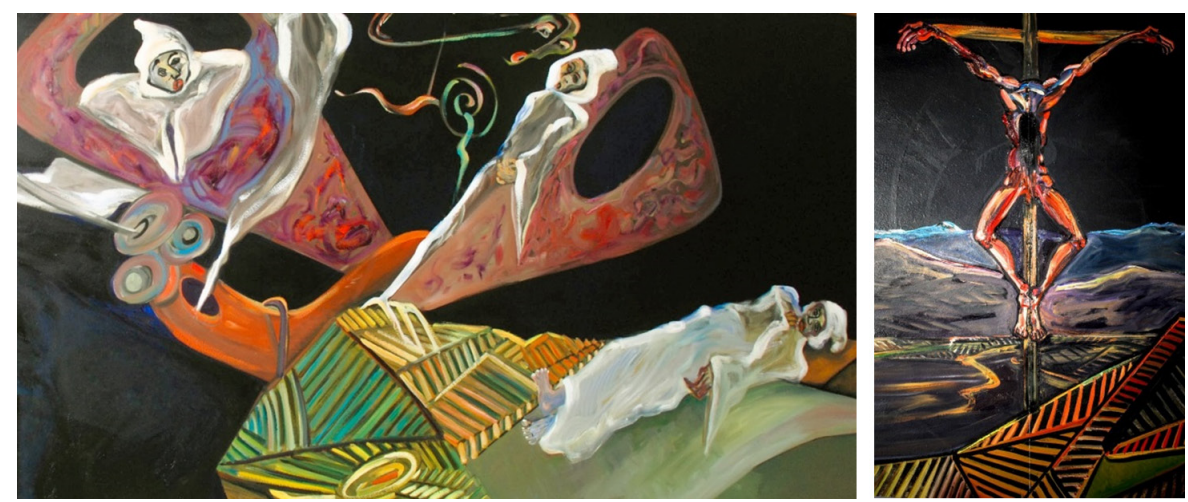

Figura 7 y 8. Detalles de Los Siete Pecados Capitales. Derecha: "La Pereza". Izquierda: "Cristo" se asoma como una aparición entre "La Ira y La Soberbia". Galería de la hospedería del monasterio de San Pedro de Cardeña. Foto: Eliana Alvoz.

EA: Cambiando un poco de tema... En la hospedería hay un Cristo perdido, solo, situado al margen del resto.

JV: Sí. Ciertamente, está un poco al margen. Se trata de un Cristo muy equilibrado [Fig. 9], estructurado, la sangre, el agua es una alegoría de la lanza de Longinos, cuando responde el cuerpo del Creador. Como diciendo metafóricamente el semen de la vida es: la sangre y el agua, por eso, hay una especie de tubo del que salen unas cosas que van hacia el corazón, y luego, el agua que cae hacia abajo. Aunque está exhibido al margen de los Pecados es del año 1971.

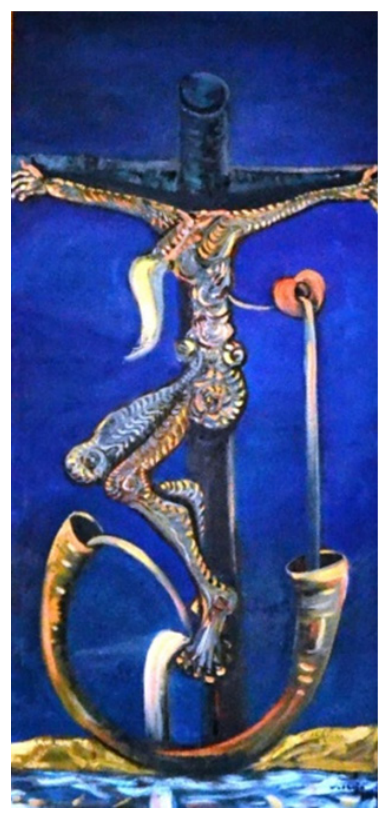

Figura 9. Juan Vallejo, Cristo, Galería de la hospedería del monasterio de San Pedro de Cardeña, 1971. Foto: Eliana Alvoz. 
EA: Las obras realizadas en Cardeña (la bóveda Imperial como Los Siete Pecados Capitales) reflejan una visión mística totalmente nueva ¿Consideras esa obra cómo uno de los mayores retos profesionales?

JV: La visión mística de mi obra en san Pedro de Cardeña, es novedosa sin duda. Desde la influencia de Goya hasta el expresionismo de Francis Bacon que tanto me seduce, existe una especie de dicotomía que establece ese expresionismo térreo y contundente que se asoma a la balconada del cenobio cisterciense. Son personajes nuevos, catárticos, compuestos, cuajado de asombro, de sustancia espiritual y orgánica que a veces se entreveran para expresar arrebatos y miradas tremendas que nos invitan a la reflexión. Como si de una angustia anudada al éxtasis se tratara.

No sé muy bien si esto, al cabo de los años, me ha supuesto el mayor reto artístico de mi vida. Me encuentro muy bien de salud, muy fuerte para acometer proyectos de esta naturaleza. Pienso que todavía puedo pintar algo grandioso, que falta algo sublime en mi carrera, que está por llegar. Espero que algún espacio monástico o de otra índole me aguarde. Aún tengo mucho que decir, y mi experiencia será un gran acicate para llevarlo a cabo.

EA: Su intervención en San Pedro de Cardeña finaliza con el encargo de la obra cidiana, en un primer momento iban a ser cuatro obras...

JV: Sí, pero al final se hicieron tres. En aquel Monasterio no había nada del Cid. Entonces el abad me dijo: Juan píntame algo - yo estaba viviendo en Madrid, en Andrés Mellado - compré unas telas e hice La despedida del Cid (1977), El entierro del Cid (homenaje a mi padre que falleció mientras lo acababa 13 de febrero de 1978) y el Ora et labora (1979). Éste último [Fig. 10] da idea de lo que es el Monasterio, el trabajo, la austeridad. En él se retrata el Padre Telesforo y el Hermano Alfonso que lleva ese guardapolvo azul remendado. Se trata de una obra de carácter surrealista.

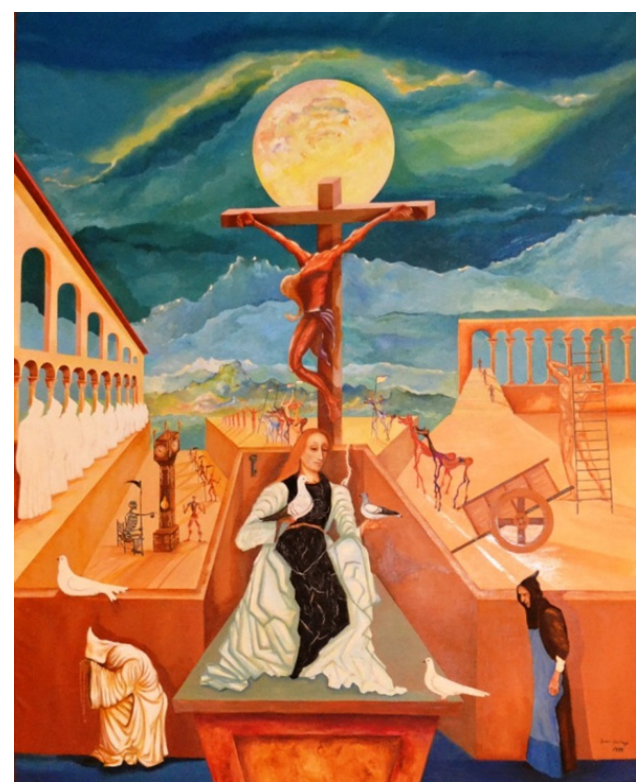

Figura 10. Ora et labora. Óleo sobre lienzo, 1979. Foto: Eliana Alvoz. 
EA: Nos consta que obras de pequeño formato decoran los entrepaños de la Biblioteca del monasterio ¿Qué temática abordan estas obras?

JV: Se tratan de óleos de formato medio de $81 \times 100$, son obras de carácter costumbrista (la cotidianeidad): bodegones, naturalezas muertas, sátiras, tentaciones, hay un retrato del Hermano Alfonso.

EA: ¿Y del Quijote no ha pintado nada para el monasterio?

JV: Los monjes tienen un almacén de obras donadas. Pues, esos del Quijote que hice se los había dado a Ángel Blanco Escudero y fue donada por él a la abadía.

EA: La regla del ora et labora fundada por San Benito de Nursia ha mutado desde la benedictina cuyo ejemplo vemos en San Pedro de Cardeña (donde has realizado obras en el refectorio y en la Sala Capitular), pasando por Cluny, para acabar con la reforma propulsada por San Bernardo de Claraval, que dio lugar al Cister ¿No te has planteado pintar en cenobios de otro carisma? ¿Por qué siempre el cister? ¿Qué tiene éste de peculiar? ¿Qué te cautiva?

JV: Pinté en el monasterio cisterciense de la Oliva, en Navarra, un gran mural en el refectorio. Fue en 1973; también hice algún cuadro más para las estancias de la abadía, pero el más importante fue el encargo de Silos donde pinté Sileuros (Europa en Silos). San Benito de Nursia, fundador de los benedictinos y autor de la Santa Regla, el Ora et labora, patrón de Europa por Pablo VI, era el protagonista. Un enorme lienzo de 37 metros cuadrados, decora la sala Capitular del monasterio junto a otros cuadros sobre la orden benedictina. También pinté en Silos una serie muy bella sobre los apóstoles y Emaús que decoró algún tiempo el refectorio. Ignoro su paradero. Las últimas noticias que tengo es que no están allí. También pinté un centenar de dibujos en técnica mixta que doné a la comunidad.

EA: ¿Alguna vez te han propuesto pintar en otros monasterios ya sea fuera del ámbito local de Burgos o en el extranjero?

$\mathrm{JV}$ : Me propusieron varios trabajos en otros monasterios, pero mi compromiso con las libertades y la Memoria Histórica, hizo que me volcara en otro tipo de misticismos.

EA: Si veíamos que el alma mater de la regla monástica benedictina se ha perfeccionado con el paso del tiempo ¿Consideras que tu obra ha evolucionado? ¿Tus obras primigenias se asemejan a algo a las de ahora? ¿Crees que beben de la misma fuente? ¿Qué es lo que te inspira a seguir pintando?

JV: Todo pintor que se precie trabaja sobre su pretérito artístico. Su numen es muy riguroso en enhebrar la obra de por venir. Somos consecuencia de tantas cosas...Es inexorable el vínculo con las ideas atrapadas en la infancia, con las primeras grafías que hacíamos apenas balbuceamos el lenguaje. Las fuentes dimanan del mismo venero. Por mucho que intentemos variar el rumbo, siempre el subconsciente emite su necesidad de emerger, aunque solo fuera bajo el manto de la influencia, de lo onírico, de eso tan enigmático que se denomina inspiración. Afortunadamente mi 
memoria es muy fresca, a veces me asombra recordar colores, sombras, paisajes, rostros que en mi infancia y adolescencia "sujetaba" en mi magín; pareciera que lo he visto hace unos minutos, que lo veo ahora mismo. Incluso los nombres, los portales, las casas, los árboles y arroyos de Gamonal por donde el campo y la siembra rodeaban el pueblo donde nací. Por eso, las fuentes en las que uno se nutre, suelen manar del pasado, de los maestros que nos subyugaron y aprendimos. Somos muchas cosas cuando pintamos, son muchos los que le pintan al unísono.

EA: Por último, y para concluir en relación a su obra en Cardeña en 1971: ¿Cómo crees que la entendieron los artistas contemporáneos y el crítico Antonio Cobos Soto $^{1}$ ? Y ¿los monjes y el abad de Cardeña Sergio del Pino Campos?

JV: Cuando pinté Cardeña, Silos, etc., se suscitaron controversias. Incluso anónimos se dirigieron a los abades para que se me prohibiera pintar en esos espacios. Es penoso comprobar cómo este país sigue siendo un vivero de envidias. Al cabo del tiempo, la mediocridad se instaló en aquellos que, anónimamente, trataron de anularme. $\mathrm{Mi}$ coraje y la certeza de que mi pintura tenía que formar parte de todas mis edades como una fusión sólida e intratable, la huida de un territorio hostil como era entonces la ciudad de Burgos a cielos más propicios, hizo que se cumpliera mi ilusión de ser un hombre pintor. Tanto el abad Sergio como el crítico Cobos Soto, no cedieron ante los detractores. El tiempo obra sobre mi obra como si de un inescrutable sueño se tratara.

Entrevista realizada el 12 y 13 de enero de 2018, en Burgos. 